\title{
Isotopic fractionation of water and its photolytic products in the atmosphere of Mars
}

\author{
Juan Alday ${ }^{1, *}$, Alexander Trokhimovskiy ${ }^{2}$, Patrick G. J. Irwin ${ }^{1}$, Colin F. Wilson ${ }^{1}$, Franck \\ Montmessin $^{3}$, Franck Lefèvre ${ }^{3}$, Anna A. Fedorova ${ }^{2}$, Denis A. Belyaev ${ }^{2}$, Kevin S. Olsen ${ }^{1}$, \\ Oleg Korablev ${ }^{2}$, Margaux Vals ${ }^{3}$, Loïc Rossi ${ }^{3}$, Lucio Baggio ${ }^{3}$, Jean-Loup Bertaux ${ }^{3}$, Andrey \\ Patrakeev $^{2}$, and Alexey Shakun ${ }^{2}$
}

\author{
${ }^{1}$ AOPP, Department of Physics, University of Oxford, Oxford, United Kingdom \\ ${ }^{2}$ Space Research Institute (IKI), Moscow, Russia \\ ${ }^{3}$ LATMOS/CNRS, Guyancourt, France \\ *corresponding author: Juan Alday (juan.aldayparejo@physics.ox.ac.uk)
}

1 ABSTRACT

The current Martian atmosphere is about five times more enriched in deuterium than Earth's, providing a direct testimony that Mars hosted vastly more water in its early youth than nowadays. Estimates of the total amount of water lost to space from the current mean $\mathrm{D} / \mathrm{H}$ value depend on a rigorous appraisal of the relative escape between deuterated and non-deuterated water. Isotopic fractionation of $\mathrm{D} / \mathrm{H}$ between the lower and the upper atmospheres of Mars has been assumed to be controlled by water condensation and photolysis, although their respective role in influencing the relative proportion of atomic $D$ and $H$ populations has remained speculative. Here we report $\mathrm{HDO}$ and $\mathrm{H}_{2} \mathrm{O}$ profiles observed by the Atmospheric Chemistry Suite (ExoMars Trace Gas Orbiter) in orbit around Mars that, once combined with expected photolysis rates, reveal the prevalence of the perihelion season for the formation of atomic $\mathrm{H}$ and $\mathrm{D}$ at altitudes relevant for escape. In addition, while condensation-induced fractionation is the main driver of variations of $\mathrm{D} / \mathrm{H}$ in water vapour, the differential photolysis of $\mathrm{HDO}$ and $\mathrm{H}_{2} \mathrm{O}$ is a more important factor in determining the isotopic composition of the dissociation products.

\section{Main text}

The isotope composition of the Martian atmosphere has often been used as a means to understand its evolution ${ }^{1}$. Assuming that Earth and Mars were assembled out of the same material, the relative enrichment of heavy isotopes in Martian atmospheric water vapour with respect to Earth suggests that the escape of water throughout the Martian history has been substantial ${ }^{2-12}$, consistent with the geomorphological and mineralogical imprints on the surface, which require the presence of liquid water on ancient Mars ${ }^{13,14}$. Although these clues indicate that water was abundant in the past, the amount that existed remains uncertain. Estimations of the size of the ancient water reservoir on Mars from its isotope composition depend not only on the present-day atmospheric ratio, but also on the net escape fractionation factor, $f$. This factor relates the efficiency of escape of $\mathrm{D}$ with respect to $\mathrm{H}$, including all fractionation processes occurring along the physical and chemical pathways by which the initial $\mathrm{H}_{2} \mathrm{O}$ and HDO molecules are decomposed and ultimately escape to space by either thermal or non-thermal means ${ }^{15-18}$.

The initial part of the process by which water escapes to space comprises the production of atomic $\mathrm{H}$ and $\mathrm{D}$ from water vapour. For a long time, this production was assumed to be sourced by long-lived molecular hydrogen formed in the lower atmosphere and slowly ascending to the upper atmosphere, where it is dissociated into $\mathrm{HCO}_{2}^{+}$and $\mathrm{H}$ by its recombination with $\mathrm{CO}_{2}^{+19}$. Molecular hydrogen in the lower atmosphere is ultimately produced in the photodissociation of $\mathrm{H}_{2} \mathrm{O}$, which gives rise to odd-hydrogen $\left(\mathrm{H}, \mathrm{OH}, \mathrm{HO}_{2}\right)$ molecules that participate in the catalytic recombination of $\mathrm{CO}_{2}$, producing $\mathrm{H}_{2}$ as a by-product of this recombination ${ }^{16}$. While this pathway gives rise to a steady supply of atomic hydrogen, observations of $\mathrm{H}$ in the upper atmosphere reveal variations not consistent with the sole production by molecular hydrogen ${ }^{20,21}$. These variations might be instead produced by the direct dissociation of water vapour in the middle and upper atmospheres by UV photons and reactions with ions ${ }^{19,22,23}$. Whether the $\mathrm{H}_{2}$ or $\mathrm{H}_{2} \mathrm{O}$-driven escape scenario is predominant, the photolysis of water vapour appears to have an important contribution. In this context, two factors can fractionate the production of deuterium relative to hydrogen: 1) the preferential photolysis of $\mathrm{H}_{2} \mathrm{O}$ molecules relative to $\mathrm{HDO}$ depletes the dissociation products in deuterium ${ }^{24}$; 2) the preferential condensation of HDO in water ice clouds ${ }^{25}$ leaves the atmosphere depleted in the heavy isotopes above the condensation level, which can impact the supply of $\mathrm{D} / \mathrm{H}$ to the upper atmosphere, if photolysis occurs above the cloud deck ${ }^{26,27}$. Both of these mechanisms are expected to fractionate the isotopic composition of atomic hydrogen, although the effectiveness of each of 
these remains unknown.

We investigate the vertical distribution of the isotope composition $\left(\mathrm{D} / \mathrm{H}\right.$ and $\left.{ }^{18} \mathrm{O} /{ }^{16} \mathrm{O}\right)$ of water vapour in the Martian atmosphere using solar occultation measurements made by the mid-infrared (MIR) channel of the Atmospheric Chemistry Suite $^{28}$ (ACS) onboard the ExoMars Trace Gas Orbiter (TGO). ACS MIR is an echelle cross dispersion spectrometer dedicated to solar occultation measurements in a spectral range between 2.2 and $4.4 \mu \mathrm{m}$. Its novel design allows the simultaneous selection of 9 to 25 contiguous diffraction orders within the entire spectral range of the instrument, achieving high resolving power $(\lambda / \Delta \lambda \sim 30,000)$ in a wide instantaneous spectral range $(0.15-0.3 \mu \mathrm{m})$. The dataset assembled for this study includes all available ACS MIR solar occultation observations made using secondary grating position 4, which allows the selection of ten diffraction orders (215-224) in a spectral range between 2.65 and $2.77 \mu \mathrm{m}\left(3600-3770 \mathrm{~cm}^{-1}\right)$, encompassing absorption bands of several isotopologues of carbon dioxide and water vapour (see Supplementary Figures 2 and 3). To date, there are 627 secondary grating position 4 solar occultations, which account for approximately $14 \%$ of all available ACS MIR observations, covering more than a full Martian year of observations and including more than half of Martian Year 34 $\left(\mathrm{MY}^{2}\right)\left(\mathrm{L}_{s}=160-360^{\circ}\right)$ and of MY35 $\left(\mathrm{Ls}=0-356^{\circ}\right)$. The observational coverage used in this dataset allows the analysis of the variations of the D/H ratio in three dimensions, including the vertical, latitudinal, and seasonal effects.

The analysis of the data and the retrieval of the atmospheric vertical profiles is performed using the NEMESIS (Nonlinear optimal Estimator for MultivariatE spectral analySIS) algorithm ${ }^{29}$, which utilises the optimal estimation framework ${ }^{30}$. In particular, the retrieval scheme is performed in two steps. First, vertical profiles of pressure and temperature are retrieved from $\mathrm{CO}_{2}$ absorption, along with the vertical distribution of the $\mathrm{H}_{2}^{16} \mathrm{O}$ volume mixing ratio. Secondly, the pressure and temperature profiles are fixed, and the retrieved $\mathrm{H}_{2}^{16} \mathrm{O}$ volume mixing ratio is used as an a priori estimate to retrieve the volume mixing ratios of $\mathrm{H}_{2}^{16} \mathrm{O}, \mathrm{H}_{2}^{18} \mathrm{O}$ and $\mathrm{HD}^{16} \mathrm{O}$, assuming an a priori isotopic composition of ${ }^{18} \mathrm{O} /{ }^{16} \mathrm{O}=1$ and $\mathrm{D} / \mathrm{H}=5$ with respect to the Vienna Standard Mean Ocean Water (VSMOW; D/H $=1.6 \times 10^{-4}$ and ${ }^{18} \mathrm{O} /{ }^{16} \mathrm{O}=2.0 \times 10^{-3}$ ), and using a spectral window suitable for the derivation of the isotopic ratios (see Figure 1). More details describing the retrieval scheme and its validation are given in the Supplementary Methods.

Figure 2 shows a summary of the climatology of the retrieved parameters from the spectra. During the observed period, both temperature and $\mathrm{H}_{2} \mathrm{O}$ volume mixing ratio profiles show drastic seasonal and latitudinal changes. During the Southern Hemisphere $(\mathrm{SH})$ spring and summer seasons $\left(\mathrm{Ls}=180-270^{\circ}\right.$ and $\left.\mathrm{L}_{s}=270-360^{\circ}\right)$ in both MY34 and MY35, Mars is close to perihelion $\left(\mathrm{L}_{s}=251^{\circ}\right)$, and the greater dust heating and proximity to the Sun intensify the Hadley circulation ${ }^{31,32}$, allowing warmer temperatures to expand to the middle atmosphere in both the northern and southern hemispheres. These greater temperatures move the hygropause (i.e., level at which water vapour saturates) upwards to higher altitudes, allowing water vapour to migrate to the middle and upper atmospheres, and reaching values of 40-80 and 20-40 ppmv at $90 \mathrm{~km}$ in the southern and northern hemispheres, respectively. The ascension of water vapour to the middle atmosphere also occurs during the Global Dust Storm (GDS) in MY34 $\left(\mathrm{L}_{s}=190-220^{\circ}\right)$, when the hygropause is moved to approximately $80 \mathrm{~km}$ in both hemispheres. This behaviour is not observed during the same period in MY35, when the altitude of the hygropause is set around 40-50 km at mid-latitudes (see Figure 2). This difference evidences the impact of dust storms, which increase the dust heating and prevent the condensation of water vapour ${ }^{33}$. During the Northern Hemisphere $(\mathrm{NH})$ spring and summer seasons $\left(\mathrm{L}_{s}=0-90^{\circ}\right.$ and $\mathrm{L}_{s}=$ $90-180^{\circ}$ ), although high water vapour abundances (> $150 \mathrm{ppmv}$ ) are observed in the NH, these are confined to altitudes below $\sim 20 \mathrm{~km}$. At high southern latitudes $\left(>60^{\circ} \mathrm{S}\right)$, during this time, very low water vapour abundances $(<1 \mathrm{ppmv})$ and temperatures $(<150 \mathrm{~K})$ are observed. These seasonal trends are in agreement with other observations ${ }^{34-37}$ and with the expectations from the simulations of a General Circulation Model $(\mathrm{GCM})^{38}$.

The measurements also depict a very dynamic behaviour of the $\mathrm{D} / \mathrm{H}$ ratio, varying from 1 to $6 \mathrm{VSMOW}$, with an isotopic ratio representative of the present-day Martian atmosphere of 4.9 \pm 0.4 VSMOW (see Extended Data Figure 1). During the $\mathrm{SH}$ summer, $\mathrm{H}_{2} \mathrm{O}$ and $\mathrm{HDO}$ in both hemispheres expand into the middle atmosphere, exhibiting isotopic ratios between 4-6 VSMOW up to 40-60 km until they reach the saturation level, where water ice clouds can form ${ }^{39,40}$. Above this level, the D/H ratio starts to decrease down to values between 1-3 VSMOW, as predicted by the preferential condensation of $\mathrm{HDO}$ over $\mathrm{H}_{2} \mathrm{O}$ during the formation of water ice clouds ${ }^{25,27}$. The presence of isotopic fractionation in condensation processes is even clearer during the NH summer, which shows a steady decrease of the D/H ratio from 4-5 VSMOW at $10 \mathrm{~km}$ down to 2-3 VSMOW at 20-30 km, due to a lower altitude of the hygropause (see Figure 2 and Extended Data Figure 2).

The variations in the $\mathrm{D} / \mathrm{H}$ ratio are found to be positively correlated with those in the water vapour volume mixing ratio (Pearson correlation coefficient of 0.7 between D/H and $\log _{10}\left(\mathrm{H}_{2} \mathrm{O}\right)$ ), as shown in Extended Data Figure 1. A logarithmic relation between $\mathrm{D} / \mathrm{H}$ and water vapour abundance is predicted by the isotope fractionation during condensation ${ }^{27}$, which appears therefore responsible for the observed variations. Similarly, the observed variations of the D/H ratio appear to be related to the atmospheric temperature: while the higher values of the D/H ratio ( $>4 \mathrm{VSMOW}$ ) are found in a wide range of temperatures $(170-210 \mathrm{~K})$, low values of $\mathrm{D} / \mathrm{H}(<3 \mathrm{VSMOW})$ are only measured for $\mathrm{T}<180 \mathrm{~K}$. This correlation corroborates 
the hypothesis of the prominent role of condensation-induced fractionation, which is predicted to increase with decreasing temperatures $\mathrm{s}^{4,5,25,41}$.

The ${ }^{18} \mathrm{O} /{ }^{16} \mathrm{O}$ is found to be much less variable than the $\mathrm{D} / \mathrm{H}$ ratio. The value representative of the present-day atmospheric ratio is found to be $1.14 \pm 0.08$ VSMOW, which is in line with values reported in previous studies ${ }^{3,11}$. We observe variations ranging between 0.9 and $1.3 \mathrm{VSMOW}$, although this level of variability is in the same range as the typical measurement uncertainty, which makes it difficult to disentangle potential variations of the isotopic ratios from statistical noise. Expectations from isotopic fractionation in condensation processes predict a preferential condensation of $\mathrm{H}_{2}^{18} \mathrm{O}$ over $\mathrm{H}_{2}^{16} \mathrm{O}$, similar to the $\mathrm{D} / \mathrm{H}$ ratio, but with a lower magnitude $25,42,43$. The absence of measured variability does not rule out the presence of fractionation processes though, since they might be smaller than, and therefore masked by the measurement uncertainty (see Extended Data Figure 1).

Estimations of how $\mathrm{H}_{2} \mathrm{O}$ and $\mathrm{HDO}$ molecules are fractionated as they are photodissociated into lighter molecules $(\mathrm{OH}$ $+\mathrm{H})$ are made with the photolysis code of the LMD-GCM ${ }^{24,44}$. These calculations are combined with ACS MIR water vapour density vertical profiles to estimate the dissociation rates, which reveal the perihelion season to be dominant in the photodissociation of water vapour, with rates approximately 10-100 times greater than those found close to aphelion (see Figure 3). Our calculations suggest that the bulk of $\mathrm{H}_{2} \mathrm{O}$ photolysis during perihelion occurs near $50-60 \mathrm{~km}$ in the southern hemisphere, while the maximum photolysis rates during aphelion are found at $10 \mathrm{~km}$ in the northern hemisphere (see Extended Data Figures 3 and 4). Photochemical models predict atomic $\mathrm{H}$ to be quickly destroyed in the lower atmosphere, while its chemical lifetime increases exponentially with altitude ${ }^{45}$. Therefore, during the aphelion season, the formed $\mathrm{H}$ will quickly be destroyed while recombining with $\mathrm{O}_{2}{ }^{46}$. However, during perihelion, the longer lifetime of most formed $\mathrm{H}$ together with the intensified atmospheric circulation can potentially transport atomic $\mathrm{H}$ to higher altitudes ${ }^{31,33}$. In fact, Chaffin et al. ${ }^{22}$ predict that an increase of the water abundance of $80 \mathrm{ppmv}$ at $60 \mathrm{~km}$ yields approximately an increase in the $\mathrm{H}$ escape flux of a factor of five, and Krasnopolsky ${ }^{19}$ suggests that the hydrogen escape flux may be approximated by a function of the water abundance at $80 \mathrm{~km}$. This result is consistent with measurements of the $\mathrm{H}$ and D Lyman- $\alpha$ brightness, representative of upper-atmospheric atomic $\mathrm{H}$ and $\mathrm{D}$ densities, which show peak values around perihelion ${ }^{47-49}$.

We calculated the fractionation factor relating the $\mathrm{D} / \mathrm{H}$ ratio in the photolysis products with respect to the mean $\mathrm{D} / \mathrm{H}$ ratio representative of water in the lower atmosphere $\left(R=(\mathrm{D} / \mathrm{H})_{\text {products }} /(\mathrm{D} / \mathrm{H})_{\text {bulk }}\right)$, taking into account the impact of both photolysis-induced fractionation $R_{p}$ (i.e., fractionation due to the difference in the photolysis cross sections of $\mathrm{HDO}$ and $\mathrm{H}_{2} \mathrm{O}$; $R_{p}=J_{\mathrm{HDO}} / J_{\mathrm{H}_{2} \mathrm{O}}$, where $J_{\mathrm{HDO}}$ and $J_{\mathrm{H}_{2} \mathrm{O}}$ are the photolysis rates of $\mathrm{HDO}$ and $\mathrm{H}_{2} \mathrm{O}$, respectively) and condensation-induced fractionation $R_{c}$ (i.e., fractionation due to the depletion in $\mathrm{D} / \mathrm{H}$ of the parent water molecules with respect to the average $\mathrm{D} / \mathrm{H}$ ratio of water in the lower atmosphere; $\left.R_{c}=(\mathrm{D} / \mathrm{H})_{\text {parent }} /(\mathrm{D} / \mathrm{H})_{\text {bulk }}\right)$. More details about how these calculations are performed are given in the Supplementary Methods. Our calculations suggest that, while the dissociation products are expected to have a $\mathrm{D} / \mathrm{H}$ ratio about 2-2.5 times lower than the average $\mathrm{D} / \mathrm{H}$ ratio in the lower atmosphere $\left(\mathrm{D} / \mathrm{H}_{\text {bulk }}=4.9 \pm 0.4 \mathrm{VSMOW}\right)$ during perihelion $(R \sim 0.4-0.5)$, the fractionation factor $R$ would decrease down to 0.2 during aphelion (see Figure $3 \mathrm{~b}$ ). However, the dissociation rates during the aphelion season are lower than during perihelion and are therefore expected to have a minor contribution to the annual average. Consequently, the annual average $\mathrm{D} / \mathrm{H}$ fractionation factor $R$ is heavily weighted towards perihelion.

While condensation-induced fractionation appears to be the main driver of the variations of the $\mathrm{D} / \mathrm{H}$ ratio in atmospheric water vapour, it has a minor influence on shaping the isotopic composition of the dissociation products as compared to photolysis-induced fractionation. During perihelion, at the altitudes at which photolysis is more efficient (40-60 km), while water vapour is still not affected by condensation $\left(R_{c} \sim 1\right)$, the photolysis-induced fractionation factor is expected to be about $R_{p} \sim 0.4-0.6$ (see Extended Data Figure 3). During aphelion, the role of condensation-induced fractionation increases with respect to perihelion $\left(R_{c} \sim 0.5-0.7\right)$, but so does the role of photolysis-induced fractionation $\left(R_{p} \sim 0.3-0.5\right)$, which increases due to the intensified photolysis near the surface (see Extended Data Figure 3). Besides, as previously mentioned, the role of the aphelion season in the dissociation of water vapour is expected to be negligible with respect to perihelion.

The calculations of the fractionation factor $R$ are representative of photolysis below $\sim 60 \mathrm{~km}$, where the ACS MIR measurements are sensitive to HDO (see Figure 2). At these altitudes, the formed $\mathrm{H}$ and D will not participate in the direct escape of these species in the upper atmosphere. Instead, most formed $\mathrm{OH}$ and $\mathrm{H}$ will ultimately recombine into $\mathrm{H}_{2}$ and $\mathrm{H}_{2} \mathrm{O}$ and contribute to escape in much longer timescales. This is consistent with the measurement of $\mathrm{D} / \mathrm{H}$ in molecular hydrogen, which was found to be approximately 2.5 times smaller than the D/H ratio in water $(R=0.4)^{16}$. Further calculations will be needed to determine the relative impact of condensation and photolysis-induced fractionation above $60 \mathrm{~km}$, where the direct photolysis of water can contribute to escape in short timescales. Our results provide new insights for resolving the old paradigm regarding the role of the different mechanisms to fractionate the $\mathrm{D} / \mathrm{H}$ ratio of water vapour in the lower atmosphere and that of its dissociation products, leading to the enrichment of $\mathrm{D} / \mathrm{H}$ in the atmosphere as it escapes into space $24,26,50$. 
Similarly, as for $\mathrm{HDO}, \mathrm{H}_{2}^{18} \mathrm{O}$ molecules are expected to have a different $\mathrm{UV}$ absorption cross-section than $\mathrm{H}_{2}^{16} \mathrm{O}$, which can impact the isotope composition of the dissociation products of water vapour and the efficiency of ${ }^{18} \mathrm{O}$ to reach the upper atmosphere $^{51}$. We estimate that, while the dissociation products are expected to be about $2-2.5$ times depleted in $\mathrm{D} / \mathrm{H}$ with respect to the ratio in water vapour in the lower atmosphere, this factor would just be 1.025 for the ${ }^{18} \mathrm{O} /{ }^{16} \mathrm{O}$ ratio $\left(R_{p}\left({ }^{18} \mathrm{O} /{ }^{16} \mathrm{O}\right)\right.$ $\sim 0.975$ ), revealing a much higher efficiency of ${ }^{18} \mathrm{O}$ to be transferred to the dissociation products with respect to $\mathrm{D}$. This might explain the dichotomy between the large enrichment in the heavy isotope of the D/H ratio ( $\sim 5$ VSMOW) as opposed to the mild enrichment in the ${ }^{18} \mathrm{O} /{ }^{16} \mathrm{O}$ ratio $(\sim 1.14 \mathrm{VSMOW})$ : while ${ }^{18} \mathrm{O}$ is efficiently transferred to the photolysis products of water vapour, $\mathrm{HDO}$ molecules are less efficiently photolysed, decreasing the $\mathrm{D} / \mathrm{H}$ ratio of the lighter species that ultimately escape to space. Therefore, as $\mathrm{H}$ and $\mathrm{O}$ escape from the Martian atmosphere, they will more efficiently enrich the $\mathrm{D} / \mathrm{H}$ ratio than the ${ }^{18} \mathrm{O} /{ }^{16} \mathrm{O}$ ratio. Nevertheless, it must also be noted that, while $\mathrm{H}_{2} \mathrm{O}$ is the major reservoir of hydrogen in the atmosphere of Mars, oxygen atoms in water vapour are expected to interact with those from $\mathrm{CO}_{2}$ and minerals in the crust, which adds an extra degree of complexity to the connection between $\mathrm{O}$ isotopic ratios and atmospheric escape. ${ }^{17,52,53}$.

\section{References}

1. Jakosky, B. M. Mars volatile evolution: Evidence from stable isotopes. Icarus 94, 14-31, 10.1016/0019-1035(91)90138-J (1991).

2. Owen, T., Maillard, J. P., de Bergh, C. \& Lutz, B. L. Deuterium on Mars: The Abundance of HDO and the Value of D/H. Science 240, 1767-1767, 10.1126/science.240.4860.1767 (1988).

3. Webster, C. R. et al. Isotope Ratios of H, C, and O in CO2 and H2O of the Martian Atmosphere. Science 341, 260-263, 10.1126/science.1237961 (2013).

4. Villanueva, G. L. et al. Strong water isotopic anomalies in the martian atmosphere: Probing current and ancient reservoirs. Science 348, 218-221, 10.1126/science.aaa3630 (2015).

5. Krasnopolsky, V. A. Variations of the $\mathrm{HDO} / \mathrm{H} 2 \mathrm{O}$ ratio in the martian atmosphere and loss of water from Mars. Icarus 257, 377-386, 10.1016/j.icarus.2015.05.021 (2015).

6. Aoki, S. et al. Seasonal variation of the $\mathrm{HDO} / \mathrm{H} 2 \mathrm{O}$ ratio in the atmosphere of Mars at the middle of northern spring and beginning of northern summer. Icarus 260, 7-22, 10.1016/j.icarus.2015.06.021 (2015).

7. Encrenaz, T. et al. A map of D/H on Mars in the thermal infrared using EXES aboard SOFIA. Astron. \& Astrophys. 586, A62, 10.1051/0004-6361/201527018 (2016).

8. Encrenaz, T. et al. New measurements of D/H on Mars using EXES aboard SOFIA. Astron. \& Astrophys. 612, A112, 10.1051/0004-6361/201732367 (2018).

9. Khayat, A. S., Villanueva, G. L., Smith, M. D. \& Guzewich, S. D. IRTF/CSHELL mapping of atmospheric HDO, H2O and D/H on Mars during northern summer. Icarus 330, 204-216, 10.1016/j.icarus.2019.04.007 (2019).

10. Vandaele, A. C. et al. Martian dust storm impact on atmospheric $\mathrm{H} 2 \mathrm{O}$ and $\mathrm{D} / \mathrm{H}$ observed by ExoMars Trace Gas Orbiter. Nature 568, 521-525, 10.1038/s41586-019-1097-3 (2019).

11. Alday, J. et al. Oxygen isotopic ratios in Martian water vapour observed by ACS MIR on board the ExoMars Trace Gas Orbiter. Astron. \& Astrophys. 630, A91, 10.1051/0004-6361/201936234 (2019).

12. Villanueva, G. L. et al. Water heavily fractionated as it ascends on Mars as revealed by ExoMars/NOMAD. Sci. Adv. 7, eabc8843, 10.1126/sciadv.abc8843 (2021).

13. Carr, M. H. \& Clow, G. D. Martian channels and valleys: Their characteristics, distribution, and age. Icarus 48, 91-117, 10.1016/0019-1035(81)90156-1 (1981).

14. Baker, V. R. Water and the martian landscape. Nature 412, 228-236, 10.1038/35084172 (2001).

15. Krasnopolsky, V. On the Deuterium Abundance on Mars and Some Related Problems. Icarus 148, 597-602, 10.1006/icar. 2000.6534 (2000).

16. Krasnopolsky, V. A. Mars' upper atmosphere and ionosphere at low, medium, and high solar activities: Implications for evolution of water. J. Geophys. Res. Planets 107, 11-1, 10.1029/2001JE001809 (2002).

17. Fox, J. L. \& Hać, A. Isotope fractionation in the photochemical escape of O from Mars. Icarus 208, 176-191, 10.1016/j. icarus.2010.01.019 (2010).

18. Cangi, E. M., Chaffn, M. S. \& Deighan, J. Higher Martian atmospheric temperatures at all altitudes increase the D/H fractionation factor and water loss. J. Geophys. Res. Planets 125, e2020JE006626, 10.1029/2020JE006626 (2020). 
19. Krasnopolsky, V. A. Photochemistry of water in the martian thermosphere and its effect on hydrogen escape. Icarus 321, 62-70, 10.1016/j.icarus.2018.10.033 (2019).

20. Clarke, J. T. et al. A rapid decrease of the hydrogen corona of Mars: the Martian Hydrogen Corona. Geophys. Res. Lett. 41, 8013-8020, 10.1002/2014GL061803 (2014).

21. Chaffin, M. S. et al. Unexpected variability of Martian hydrogen escape. Geophys. Res. Lett. 41, 314-320, 10.1002/ 2013GL058578 (2014).

22. Chaffin, M., Deighan, J., Schneider, N. \& Stewart, A. Elevated atmospheric escape of atomic hydrogen from Mars induced by high-altitude water. Nat. Geosci. 10, 174-178, 10.1038/ngeo2887 (2017).

23. Stone, S. W. et al. Hydrogen escape from Mars is driven by seasonal and dust storm transport of water. Science 370, 824-831, 10.1126/science.aba5229 (2020).

24. Cheng, B.-M. et al. Photo-induced fractionation of water isotopomers in the Martian atmosphere. Geophys. Res. Lett. 26, 3657-3660, 10.1029/1999GL008367 (1999).

25. Merlivat, L. \& Nief, G. Fractionnement isotopique lors des changements d'état solide-vapeur et liquide-vapeur de l'eau à des températures inférieures à $0^{\circ} \mathrm{C}$. Tellus 19, 122-127, 10.1111/j.2153-3490.1967.tb01465.x (1967).

26. Bertaux, J.-L. \& Montmessin, F. Isotopic fractionation through water vapor condensation: The Deuteropause, a cold trap for deuterium in the atmosphere of Mars. J. Geophys. Res. Planets 106, 32879-32884, 10.1029/2000JE001358 (2001).

27. Montmessin, F., Fouchet, T. \& Forget, F. Modeling the annual cycle of HDO in the Martian atmosphere. J. Geophys. Res. Planets 110, E03006, 10.1029/2004JE002357 (2005).

28. Korablev, O. et al. The Atmospheric Chemistry Suite (ACS) of Three Spectrometers for the ExoMars 2016 Trace Gas Orbiter. Space Sci. Rev. 214, 7, 10.1007/s11214-017-0437-6 (2018).

29. Irwin, P. et al. The NEMESIS planetary atmosphere radiative transfer and retrieval tool. J. Quant. Spectrosc. Radiat. Transf. 109, 1136-1150, 10.1016/j.jqsrt.2007.11.006 (2008).

30. Rodgers, C. D. Inverse Methods for Atmospheric Sounding: Theory and Practice, vol. 2 of Series on Atmospheric, Oceanic and Planetary Physics (World Scientific, 2000).

31. Shaposhnikov, D. S., Medvedev, A. S., Rodin, A. V. \& Hartogh, P. Seasonal Water "Pump" in the Atmosphere of Mars: Vertical Transport to the Thermosphere. Geophys. Res. Lett. 46, 4161-4169, 10.1029/2019GL082839 (2019).

32. Olsen, K. S. et al. The vertical structure of $\mathrm{CO}$ in the Martian atmosphere from the ExoMars Trace Gas Orbiter. Nat. Geosci. 14, 67-71, 10.1038/s41561-020-00678-w (2021).

33. Neary, L. et al. Explanation for the increase in high-altitude water on Mars observed by NOMAD during the 2018 global dust storm. Geophys. Res. Lett. 47, e2019GL084354, 10.1029/2019GL084354 (2020).

34. Trokhimovskiy, A. et al. Mars' water vapor mapping by the SPICAM IR spectrometer: Five martian years of observations. Icarus 251, 50-64, 10.1016/j.icarus.2014.10.007 (2015).

35. Fedorova, A. A. et al. Stormy water on Mars: The distribution and saturation of atmospheric water during the dusty season. Science 367, 297-300, 10.1126/science.aay9522 (2020).

36. Aoki, S. et al. Water Vapor Vertical Profiles on Mars in Dust Storms Observed by TGO/NOMAD. J. Geophys. Res. Planets 124, 3482-3497, 10.1029/2019JE006109 (2019).

37. Fedorova, A. et al. Multi-annual monitoring of the water vapor vertical distribution on Mars by SPICAM on Mars Express. J. Geophys. Res. Planets 126, e2020JE006616, 10.1029/2020JE006616 (2020).

38. Montmessin, F., Forget, F., Rannou, P., Cabane, M. \& Haberle, R. M. Origin and role of water ice clouds in the Martian water cycle as inferred from a general circulation model. J. Geophys. Res. Planets 109, E10004, 10.1029/2004JE002284 (2004).

39. Liuzzi, G. et al. Strong Variability of Martian Water Ice Clouds During Dust Storms Revealed From ExoMars Trace Gas Orbiter/NOMAD. J. Geophys. Res. Planets 125, e2019JE006250, 10.1029/2019JE006250 (2020).

40. Luginin, M. et al. Properties of Water Ice and Dust Particles in the Atmosphere of Mars During the 2018 Global Dust Storm as Inferred From the Atmospheric Chemistry Suite. J. Geophys. Res. Planets 125, e2020JE006419, 10.1029/2020JE006419 (2020).

41. Lamb, K. D. et al. Laboratory measurements of $\mathrm{HDO} / \mathrm{H}_{2} \mathrm{O}$ isotopic fractionation during ice deposition in simulated cirrus clouds. Proc. Natl. Acad. Sci. 114, 5612-5617, 10.1073/pnas.1618374114 (2017). 
42. Majoube, M. Fractionation Factor of $18 \mathrm{O}$ between Water Vapour and Ice. Nature 226, 1242-1242, 10.1038/2261242a0 (1970).

43. Casado, M. et al. Experimental determination and theoretical framework of kinetic fractionation at the water vapour-ice interface at low temperature. Geochimica et Cosmochimica Acta 174, 54-69, 10.1016/j.gca.2015.11.009 (2016).

44. Lefèvre, F. Three-dimensional modeling of ozone on Mars. J. Geophys. Res. 109, E07004, 10.1029/2004JE002268 (2004).

45. González-Galindo, F. Extension of a Martian general circulation model to thermospheric altitudes: UV heating and photochemical models. J. Geophys. Res. 110, E09008, 10.1029/2004JE002312 (2005).

46. Lefèvre, F. \& Krasnopolsky, V. Atmospheric Photochemistry. In Haberle, R. M., Clancy, R. T., Forget, F., Smith, M. D. \& Zurek, R. W. (eds.) The Atmosphere and Climate of Mars, 405-432, 10.1017/9781139060172.013 (Cambridge University Press, Cambridge, 2017).

47. Bhattacharyya, D., Clarke, J. T., Bertaux, J.-L., Chaufray, J.-Y. \& Mayyasi, M. A strong seasonal dependence in the Martian hydrogen exosphere. Geophys. Res. Lett. 42, 8678-8685, 10.1002/2015GL065804 (2015).

48. Halekas, J. S. Seasonal variability of the hydrogen exosphere of Mars: Mars Hydrogen. J. Geophys. Res. Planets 122, 901-911, 10.1002/2017JE005306 (2017).

49. Clarke, J. T. et al. Variability of $\mathrm{D}$ and $\mathrm{H}$ in the Martian upper atmosphere observed with the MAVEN IUVS echelle channel. J. Geophys. Res. Space Phys. 122, 2336-2344, 10.1002/2016JA023479 (2017).

50. Krasnopolsky, V. A., Mumma, M. J. \& Gladstone, G. R. Detection of Atomic Deuterium in the Upper Atmosphere of Mars. Science 280, 1576-1580, 10.1126/science.280.5369.1576 (1998).

51. Miller, C. E. \& Yung, Y. L. Photo-induced isotopic fractionation. J. Geophys. Res. Atmospheres 105, 29039-29051, 10.1029/2000JD900388 (2000).

52. Jakosky, B. M. \& Phillips, R. J. Mars' volatile and climate history. Nature 412, 237-244, 10.1038/35084184 (2001).

53. Jakosky, B. M., Pepin, R. O., Johnson, R. E. \& Fox, J. Mars Atmospheric Loss and Isotopic Fractionation by Solar-WindInduced Sputtering and Photochemical Escape. Icarus 111, 271-288, 10.1006/icar.1994.1145 (1994).

54. Gordon, I. et al. The HITRAN2016 molecular spectroscopic database. J. Quant. Spectrosc. Radiat. Transf. 203, 3-69, 10.1016/j.jqst.2017.06.038 (2017).

55. Régalia, L. et al. Laboratory measurements and calculations of line shape parameters of the $\mathrm{H} 2 \mathrm{O}-\mathrm{CO} 2$ collision system. $J$. Quant. Spectrosc. Radiat. Transf. 231, 126-135, 10.1016/j.jqsrt.2019.04.012 (2019).

56. Devi, V. M. et al. Line parameters for CO2- and self-broadening in the 1 band of HD16O. J. Quant. Spectrosc. Radiat. Transf. 203, 133-157, 10.1016/j.jqsrt.2017.01.032 (2017).

57. Devi, V. M. et al. Line parameters for CO2 broadening in the 2 band of HD16O. J. Quant. Spectrosc. Radiat. Transf. 187, 472-488, 10.1016/j.jqsrt.2016.10.004 (2017).

58. Devi, V. M. et al. Line parameters for CO2- and self-broadening in the 3 band of HD16O. J. Quant. Spectrosc. Radiat. Transf. 203, 158-174, 10.1016/j.jqsrt.2017.02.020 (2017).

59. Forget, F. et al. Improved general circulation models of the Martian atmosphere from the surface to above $80 \mathrm{~km}$. $J$. Geophys. Res. Planets 104, 24155-24175, 10.1029/1999JE001025 (1999).

60. Quémerais, E. et al. Stellar occultations observed by SPICAM on Mars Express. J. Geophys. Res. 111, E09S04, 10.1029/2005JE002604 (2006).

61. Montmessin, F. et al. Stellar occultations at UV wavelengths by the SPICAM instrument: Retrieval and analysis of Martian haze profiles. J. Geophys. Res. 111, E09S09, 10.1029/2005JE002662 (2006).

62. Irwin, P. G. et al. Probable detection of hydrogen sulphide (H2S) in Neptune's atmosphere. Icarus 321, 550-563, 10.1016/j.icarus.2018.12.014 (2019).

\section{Acknowledgements}

The ExoMars mission is a joint mission of the European Space Agency (ESA) and Roscosmos. The ACS experiment is led by the Space Research Institute (IKI) in Moscow, assisted by LATMOS in France. This work was funded by Roscosmos, the National Centre for Space Studies of France (CNES), the Ministry of Science and Education of Russia, the Natural Sciences and Engineering Research Council of Canada (NSERC) (PDF 178 - 516895 - 2018), and the UK Space Agency (ST/T002069/1, ST/R001502/1 and ST/P001572/1). L.R. acknowledges the support he received from the Excellence Laboratory 
"Exploration Spatiale des Environnements Planétaires (ESEP)" and from CNES. M.V. is supported by DIM ACAV labelled by the Île-de-France region in support for the research (Domaine d'Intérêt Majeur, Astrophysique et Conditions d'Apparition de la Vie). Science operations are funded by Roscosmos and ESA.

\section{Author Contributions}

Atmospheric retrievals from the ACS MIR spectra and interpretation of the retrieved parameters were performed by JA. AT, PI, CW, FM, AF, DB and KO provided input and aid on spectral fitting and retrievals. Processing of the spectra is done at LATMOS by LB and at IKI by AT. AF provided ACS NIR profiles for comparison and validation of the dataset. FL generated the photolysis rates of water vapour. FM, FL, OK, MV, LR and JLB provided input on the analysis and interpretation of the retrieved atmospheric parameters. The ACS instrument was operated by AT, AP and AS. All co-authors have contributed to the preparation of the manuscript.

\section{Competing interests}

The authors declare no competing interests.

\section{Methods}

\section{Retrieval scheme}

The retrieval scheme is performed in two steps. First of all, the pressure and temperature profiles are retrieved from the $\mathrm{CO}_{2}$ absorption in diffraction order 223, while the vertical profile of $\mathrm{H}_{2}^{16} \mathrm{O}$ volume mixing ratio is retrieved from diffraction order 224. Secondly, the pressure and temperature profiles are fixed, and the retrieved $\mathrm{H}_{2}^{16} \mathrm{O}$ volume mixing ratio is used as an a priori estimate to retrieve the volume mixing ratios of $\mathrm{H}_{2}^{16} \mathrm{O}, \mathrm{H}_{2}^{18} \mathrm{O}$ and $\mathrm{HD}^{16} \mathrm{O}$ in diffraction order 224, assuming an a priori isotopic composition of ${ }^{18} \mathrm{O} /{ }^{16} \mathrm{O}=1$ and $\mathrm{D} / \mathrm{H}=5$ with respect to VSMOW, and using a spectral window suitable for the derivation of the isotopic ratios. All gaseous absorption is modelled using pre-computed look-up tables using line-by-line modelling. The absorption of $\mathrm{CO}_{2}$ is modelled using the spectroscopic parameters listed in the 2016 edition of the HITRAN database ${ }^{54}$. In the case of $\mathrm{H}_{2} \mathrm{O}$ we use spectroscopic parameters suitable for a $\mathrm{CO}_{2}$-rich atmosphere ${ }^{55-58}$.

Pressure and temperature profiles are retrieved from the $\mathrm{CO}_{2}$ absorption under the assumptions of a known $\mathrm{CO}_{2}$ volume mixing ratio, which is obtained from the Mars Climate Database (MCD $)^{59}$, and an atmosphere in hydrostatic equilibrium. Traditionally, this retrieval technique consisted of retrieving a density profile from $\mathrm{CO}_{2}$ absorption, and deriving the pressure and temperature profiles from the hydrostatic and ideal gas laws ${ }^{60,61}$. In this study, the same assumptions are made, but retrieving a continuous profile of temperature and the pressure at a given tangent height $p\left(z_{r}\right)$. The rest of the pressure levels are re-computed based on the hydrostatic equation given by

$$
p(z)=p\left(z_{r}\right) \cdot \exp \left(-\int_{z_{r}}^{z} \frac{g(\bar{z}) M(\bar{z})}{T(\bar{z}) k_{B}} d \bar{z}\right)
$$

where $g(z)$ is the gravity, $M(z)$ is the molecular mass and $k_{B}$ is the Boltzmann constant $\left(k_{B}=1.38 \times 10^{-23} \mathrm{~J} \mathrm{~K}^{-1}\right)$. This retrieval procedure has the advantage of updating the temperatures in each iteration, and consequently updating the temperature dependence of the strength of the different absorption lines. In order to perform these retrievals, a spectral window in diffraction order 223 between 3741 and $3753 \mathrm{~cm}^{-1}$ is selected, choosing a row from the detector frame corresponding to maximum intensity, which yields the highest signal-to-noise ratio (SNR).

The initial retrieval of the vertical distribution of $\mathrm{H}_{2}^{16} \mathrm{O}$ volume mixing ratio is also performed using the maximum-intensity row, but using a spectral window between 3759.5 and $3767 \mathrm{~cm}^{-1}$ in diffraction order 224, which encompasses strong lines of $\mathrm{H}_{2}^{16} \mathrm{O}$ visible up to high altitudes $\left(>100 \mathrm{~km}\right.$ ). Comparison of the retrieved $\mathrm{H}_{2}^{16} \mathrm{O}$ with those derived from simultaneous measurements by ACS NIR ${ }^{35}$ using the absorption band at $1.38 \mu \mathrm{m}$ revealed a bias between the retrieved water vapour abundance using both datasets when observing high water vapour densities (see Supplementary Figure 4). This bias is presumably related to the saturation of the water vapour absorption lines, which impact the sensitivity of the line along the line-of-sight. In order to reconcile the retrievals from both datasets, we select a smaller spectral window $\left(3763-3765.4 \mathrm{~cm}^{-1}\right)$ including weaker absorption lines of $\mathrm{H}_{2}^{16} \mathrm{O}$. In this case, the retrievals are in good agreement with those retrieved from ACS NIR spectra at low altitudes (see Supplementary Figure 4). 
The retrieval of the $\mathrm{D} / \mathrm{H}$ and ${ }^{18} \mathrm{O} /{ }^{16} \mathrm{O}$ isotope ratios is performed using the spectral window between 3763 and $3765.4 \mathrm{~cm}^{-1}$ in diffraction order 224. However, in this case, given the smaller number and strength of the absorption lines, five different rows from the detector frame are independently retrieved and later combined, increasing the effective vertical resolution of the measurements, as well as the confidence of the retrievals. The independent retrieved profiles of $\mathrm{H}_{2}^{16} \mathrm{O}, \mathrm{H}_{2}^{18} \mathrm{O}$ and $\mathrm{HD}^{16} \mathrm{O}$ volume mixing ratio are combined using a weighted average, in which the weights are given by the inverse of the retrieved variance at each altitude $\left(\sigma(z)^{-2}\right)$, after applying a correction to mitigate the effect of the a priori uncertainty in the retrieval errors ${ }^{11,62}$. The uncertainty of the weighted-average profiles is calculated considering not only the retrieved uncertainties of each independent retrieval, but also the dispersion of each of the independent retrieved profiles, which is considered to provide a more accurate representation of the true uncertainty of the retrieval (see Supplementary Figure 5).

Once the vertical profiles of the $\mathrm{H}_{2}^{16} \mathrm{O}, \mathrm{H}_{2}^{18} \mathrm{O}$ and $\mathrm{HD}^{16} \mathrm{O}$ mixing ratios are calculated, it is possible to derive the $\mathrm{D} / \mathrm{H}$ and ${ }^{18} \mathrm{O} /{ }^{16} \mathrm{O}$ isotopic ratios following $\mathrm{D} / \mathrm{H}=\frac{\left[\mathrm{HD}^{16} \mathrm{O}\right]}{2\left[\mathrm{H}_{2}^{16} \mathrm{O}\right]}$ and ${ }^{18} \mathrm{O} /{ }^{16} \mathrm{O}=\frac{\left[\mathrm{H}_{2}^{18} \mathrm{O}\right]}{\left[\mathrm{H}_{2}^{16} \mathrm{O}\right]}$, which are then normalised using the Vienna Standard Mean Ocean Water (VSMOW; D/H $=1.6 \times 10^{-4}$ and ${ }^{18} \mathrm{O} /{ }^{16} \mathrm{O}=2.0 \times 10^{-3}$ ). The uncertainties in the isotope ratios are then

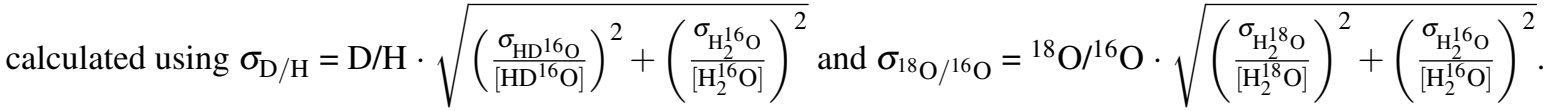

Although the retrievals made with the spectral window between 3763 and $3765.4 \mathrm{~cm}^{-1}$ are accurate at the altitudes relevant for the calculation of the isotopic ratios, the absorption lines disappear at lower altitudes than those in the spectral window between 3759.5 and $3767 \mathrm{~cm}^{-1}$. In order to derive $\mathrm{H}_{2}^{16} \mathrm{O}$ profiles with low uncertainties at all altitudes, we calculate the weighted average of the retrievals made with both spectral windows. These averaged profiles are validated against simultaneous ACS NIR measurements.

\section{Estimation of the average $\mathrm{D} / \mathrm{H}$ and ${ }^{18} \mathrm{O} /{ }^{16} \mathrm{O}$ isotopic ratios}

Understanding the variability of the isotopic ratios is essential to disentangle the values inferred from localised measurements, which are subject to fractionating processes, and the isotopic ratio representative of the Martian atmosphere. Extended Data Figure 1 shows a histogram of the measured values with uncertainties lower than 0.8 VSMOW for the D/H ratio, and 0.13 VSMOW for the ${ }^{18} \mathrm{O} /{ }^{16} \mathrm{O}$ isotope ratio, as well as their relation to other atmospheric parameters.

The observed values of the $\mathrm{D} / \mathrm{H}$ ratio show variability ranging from 1-2 to 5-6 VSMOW, with uncertainties typically lying within 0.3-0.5 VSMOW. The estimation of the $\mathrm{D} / \mathrm{H}$ ratio representative of the present-day Martian atmosphere requires the subtraction of climatological effects that impact the isotopic composition at certain times and locations. Climatological fractionation effects are expected to be minimal when observing high temperatures and water vapour abundances, when water is fully vaporised and free from condensation ${ }^{4}$. Under these conditions, most of the observations yield $\mathrm{D} / \mathrm{H}$ ratios between 4 and 5 VSMOW, with the most frequent value being equal to 4.9 VSMOW (see Extended Data Figure 1). Larger values of the D/H ratio (5-6 VSMOW) are observed in certain instances, although this may simply be an artefact due to the intrinsic uncertainty of the measurements ( $\sigma \sim 0.4$ VSMOW), as shown in Extended Data Figure 1. Therefore, we estimate the value representative of the present-day atmosphere to be $\mathrm{D} / \mathrm{H}=4.9 \pm 0.4$ VSMOW.

In the case of the ${ }^{18} \mathrm{O} /{ }^{16} \mathrm{O}$ isotope ratio, the observed variations are smaller than those observed in $\mathrm{D} / \mathrm{H}$, ranging from approximately 0.9 to $1.3 \mathrm{VSMOW}$, and showing no apparent correlation with water abundance or temperature (see Extended Data Figure 1). With typical uncertainties lying between 0.08 and 0.12 VSMOW, it is not possible to disentangle potential variations of the ${ }^{18} \mathrm{O} /{ }^{16} \mathrm{O}$ isotope ratio in the Martian atmosphere from the statistical noise of the instrument. From the measured ${ }^{18} \mathrm{O} /{ }^{16} \mathrm{O}$ isotope ratios throughout more than one Martian year, we estimate the ${ }^{18} \mathrm{O} /{ }^{16} \mathrm{O}$ isotope ratio representative of the Martian atmosphere to be $1.14 \pm 0.08 \mathrm{VSMOW}$, where the uncertainty corresponds to the lower bound of the typical measured uncertainties. Within the observed variations, our results are consistent with the measurement made with the Sample Analysis at Mars (SAM) instrument on the Curiosity Rover, which revealed an enrichment of the ${ }^{18} \mathrm{O} /{ }^{16} \mathrm{O}$ isotope ratio of $1.084 \pm 0.010$ VSMOW $^{3}$, and with previous solar occultation measurements made with ACS MIR secondary grating position 5, which yielded a value of $1.20 \pm 0.08$ VSMOW $^{11}$.

\section{Estimation of the fractionation factor between water vapour and its photolysis products}

Accurate estimations of the total amount of water vapour lost throughout Martian history from isotopic measurements require an understanding of the relative efficiency of the different isotopologues to escape into space. This relative efficiency is represented by the fractionation factor, $f$, which includes all fractionating processes from the start as $\mathrm{H}_{2} \mathrm{O}$ molecules, until they escape into 
space by either thermal or non-thermal means ${ }^{15,16,18}$. The escape fractionation factor is defined as

$$
f=\frac{(\mathrm{D} / \mathrm{H})_{\text {escape }}}{(\mathrm{D} / \mathrm{H})_{\text {bulk }}}=\frac{\phi_{\mathrm{D}} / \phi_{\mathrm{H}}}{\left([\mathrm{HDO}] / 2\left[\mathrm{H}_{2} \mathrm{O}\right]\right)_{\text {bulk }}},
$$

where $(D / H)_{\text {escape }}$ represents the ratio of escaping fluxes for deuterium $\left(\phi_{\mathrm{D}}\right)$ and hydrogen $\left(\phi_{\mathrm{H}}\right)$, and $(\mathrm{D} / \mathrm{H})_{\text {bulk }}$ represents the value of the $\mathrm{D} / \mathrm{H}$ ratio representative of the Martian lower atmosphere, which we estimate to be $(\mathrm{D} / \mathrm{H})_{\text {bulk }}=4.9 \pm 0.4 \mathrm{VSMOW}$. The first part of this escape process includes the photolysis of $\mathrm{H}_{2} \mathrm{O}$, giving rise to $\mathrm{OH}$ and $\mathrm{H}$. The $\mathrm{D} / \mathrm{H}$ ratio of the photolysis products may be estimated using

$$
(\mathrm{D} / \mathrm{H})_{\text {products }}(z)=(\mathrm{D} / \mathrm{H})_{\text {parent }}(z) \cdot \frac{J_{\mathrm{HDO}}(z)}{J_{\mathrm{H}_{2} \mathrm{O}}(z)},
$$

where $(\mathrm{D} / \mathrm{H})_{\text {parent }}$ represents the $\mathrm{D} / \mathrm{H}$ ratio of the parent $\mathrm{H}_{2} \mathrm{O}$ molecules and $J_{\mathrm{HDO}}$ and $J_{\mathrm{H}_{2} \mathrm{O}}$ are the photolysis rates of $\mathrm{HDO}$ and $\mathrm{H}_{2} \mathrm{O}$ in s${ }^{-1}$, respectively. Note that the $\mathrm{D} / \mathrm{H}$ ratio of the parent molecules being photolysed might be different from the $\mathrm{D} / \mathrm{H}$ ratio of the bulk of the atmosphere if water vapour is fractionated in the lower atmosphere, leading to a localised enrichment or depletion with respect to the average lower atmosphere value. Therefore, the fractionation factor $R$ between the isotopic composition of the photolysis products and that of the bulk of the atmosphere can be calculated as

$$
R(z)=\frac{(\mathrm{D} / \mathrm{H})_{\text {products }}}{(\mathrm{D} / \mathrm{H})_{\text {bulk }}}=\frac{(\mathrm{D} / \mathrm{H})_{\text {parent }}}{(\mathrm{D} / \mathrm{H})_{\text {bulk }}} \cdot \frac{J_{\mathrm{HDO}}(z)}{J_{\mathrm{H}_{2} \mathrm{O}}(z)} .
$$

Therefore, it is the combination of two factors:

- The fractionation between the $\mathrm{D} / \mathrm{H}$ ratio of the atmospheric bulk representative of the Martian lower atmosphere, and the $\mathrm{D} / \mathrm{H}$ ratio of the parent $\mathrm{H}_{2} \mathrm{O}$ molecules, which might be subject to fractionation processes occurring in the lower atmosphere. Given that the observed variations in the $\mathrm{D} / \mathrm{H}$ ratio in $\mathrm{H}_{2} \mathrm{O}$ appear to be consistent with the expectations from condensation-induced fractionation, this factor represents the effect that condensation processes have in fractionating the isotopic composition between the bulk and the photolysis products, and is given by

$$
R_{c}(z)=\frac{(\mathrm{D} / \mathrm{H})_{\text {parent }}}{(\mathrm{D} / \mathrm{H})_{\text {bulk }}} .
$$

- The fractionation inherent in the photolysis of $\mathrm{H}_{2} \mathrm{O}$, which differentiates between the $\mathrm{H}_{2} \mathrm{O}$ and $\mathrm{HDO}$ because of their different ultraviolet cross sections ${ }^{24}$ (see Supplementary Figure 9). Therefore, the fractionation factor inherent in the photolysis mechanism is given by

$$
R_{p}(z)=\frac{J_{\mathrm{HDO}}(z)}{J_{\mathrm{H}_{2} \mathrm{O}}(z)} .
$$

In order to estimate the efficiency of these processes to fractionate the isotopes during their photodissociation, the absorption cross-sections of $\mathrm{H}_{2} \mathrm{O}$ and $\mathrm{HDO}$ are implemented in the photolysis model of the LMD-GCM ${ }^{24,44}$. The middle panel in Supplementary Figure 9 shows the photolysis rates of $\mathrm{H}_{2} \mathrm{O}$ and $\mathrm{HDO}$ calculated for four solar zenith angles $\left(\mathrm{SZA}=0^{\circ}, 30^{\circ}\right.$, $60^{\circ}, 85^{\circ}$ ), and at a Sun-Mars distance of 1.52 astronomical units (AU). At high altitudes, the photolysis rates of $\mathrm{HDO}$ and $\mathrm{H}_{2} \mathrm{O}$ are dominated by the absorption at wavelengths $\lambda<180 \mathrm{~nm}$, which exhibit similar cross-sections, leading to little fractionation. At lower altitudes, the absorption by $\mathrm{CO}_{2}$ becomes important, impeding photons with $\lambda<180 \mathrm{~nm}$ to penetrate to the lower altitudes. Instead, the photolysis of $\mathrm{H}_{2} \mathrm{O}$ and $\mathrm{HDO}$ at lower altitudes is driven by photons with $\lambda>180 \mathrm{~nm}$, which yield lower photolysis rates due the lower absorption cross-section at these wavelengths, but higher fractionation between the two isotopologues. 
In order to get an insight into the importance of seasonal effects on the photolysis of water and its isotopic fractionation the photolysis rates from the model at SZA $=60^{\circ}$, representative of mean dayside conditions, are scaled to the relevant Sun-Mars distance, and multiplied by the water vapour number densities retrieved from the ACS MIR spectra during the summer seasons in the southern and northern hemispheres (see Extended Data Figure 3a). These estimated dissociation rates show very different seasonal behaviours. During the SH summer, the stronger Hadley circulation allows water to expand into the middle atmosphere in both hemispheres, where photolysis increases, reaching a maximum of $\mathrm{H}_{2} \mathrm{O}$ dissociation rates at approximately $50 \mathrm{~km}$ in the SH $\left(10^{4}-10^{5} \mathrm{~cm}^{-3} \mathrm{~s}^{-1}\right)$, and at about $40 \mathrm{~km}$ in the $\mathrm{NH}\left(10^{3}-10^{4} \mathrm{~cm}^{-3} \mathrm{~s}^{-1}\right)$. On the other hand, during the $\mathrm{NH}$ summer, the lower altitude of the hygropause confines water vapour to the near-surface, where photolysis is very inefficient, yielding maximum dissociation rates at $10 \mathrm{~km}\left(10^{3} \mathrm{~cm}^{-3} \mathrm{~s}^{-1}\right)$. The column-integrated photolysis rates are also shown in Extended Data Figure $3 \mathrm{~b}$ for the perihelion and aphelion seasons observed with ACS MIR. These calculations evidence the prevalence of the perihelion season for the dissociation of water, with rates between 10 and 100 times higher than those found during aphelion.

The lower panels in Extended Data Figure 3c show the fractionation factors $R$ associated with condensation-induced and photolysis-induced fractionation. It is shown that during the perihelion season, condensation-induced fractionation is not effective at $50 \mathrm{~km}\left(R_{c} \sim 1\right)$, where the dissociation rates peak. At this altitude, the photolysis-induced fractionation factor $\left(R_{p}\right)$ is between 0.4 and 0.5 , meaning that the photolysis products will be depleted in $\mathrm{D} / \mathrm{H}$ by a factor of 2-2.5 with respect to the average $\mathrm{D} / \mathrm{H}$ of water vapour in the lower atmosphere. During the aphelion season, photodissociation of water vapour peaks closer to the surface, and both condensation-induced and photolysis-induced fractionation become more important.

Similarly, the lowermost panels in Extended Data Figure 3d show the fractionation factors integrated over the column. However, while the calculation of the photolysis-induced column-integrated fractionation factor can be performed using all altitudes in which $\mathrm{H}_{2} \mathrm{O}$ is observed, the condensation-induced fractionation factor can just be calculated using the altitudes at which the measurements are sensitive to HDO, and missing part of the column. Therefore, the condensation-induced fractionation factor is just shown when the column-integrated photolysis rates where the measurements are sensitive to HDO (yellow points in Extended Data Figure 3b) are at least $75 \%$ of those using all altitudes in which $\mathrm{H}_{2} \mathrm{O}$ is observed (red points in Extended Data Figure 3b). The results show a higher fractionation factor during the aphelion season by both photolysis-induced and condensation-induced fractionation, as compared to the perihelion season. However, as most of the photodissociation of water vapour molecules occurs during perihelion, the average fractionation factor $R$ is expected to be heavily weighted towards perihelion.

In order to calculate the seasonal evolution of the column-integrated photolysis rates and fractionation factor (see Figure 3 and Extended Data Figure 4), these are binned in $\mathrm{L}_{s}$ with a step of $10^{\circ}$. The average fractionation factor $R$ in each bin is calculated using the column-integrated photolysis rate as a weight. In order to visualise the relative role of photolysis-induced fractionation and condensation-induced fractionation in Figure 3, we calculate their relative contribution to the total fractionation factor $R$ using $C_{p}(\%)=\frac{1-R_{p}}{2-\left(R_{p}+R_{c}\right)} \cdot 100$ and $C_{c}(\%)=\frac{1-R_{c}}{2-\left(R_{p}+R_{c}\right)} \cdot 100$.

Similarly, as for HDO, $\mathrm{H}_{2}^{18} \mathrm{O}$ molecules are expected to have a different $\mathrm{UV}$ absorption cross-section than $\mathrm{H}_{2}^{16} \mathrm{O}$, which can impact the isotope composition of the dissociation products of water vapour and the efficiency of ${ }^{18} \mathrm{O}$ to reach the upper atmosphere. To our knowledge, there are no available cross-sections for $\mathrm{H}_{2}^{18} \mathrm{O}$. However, theoretical methods ${ }^{51}$ to quantify the photo-induced isotopic fractionation predict most noticeable differences in the absorption cross-sections of $\mathrm{H}_{2}^{18} \mathrm{O}$ and $\mathrm{H}_{2}^{16} \mathrm{O}$ for wavelengths $\lambda>180 \mathrm{~nm}$, similar to the $\mathrm{H}_{2} \mathrm{O}-\mathrm{HDO}$ dichotomies (see Supplementary Figure 9). However, while the enrichment function of the cross-sections of $\mathrm{HD}^{16} \mathrm{O}$ over $\mathrm{H}_{2}^{16} \mathrm{O}\left(\varepsilon(\lambda)=\left(\frac{\sigma_{\mathrm{HDO}}}{\sigma_{\mathrm{H}_{2} \mathrm{O}}}-1\right) \cdot 100\right)$ is about $\varepsilon=-60 \%$ for $\lambda>180 \mathrm{~nm}$, it is only about $\varepsilon=-2.5 \%$ in the case of $\mathrm{H}_{2}^{18} \mathrm{O}$. If considering that most of the dissociation of water occurs during the perihelion season between $40-60 \mathrm{~km}$, while $\mathrm{H}_{2}^{16} \mathrm{O}$ molecules are about 2.5 times more efficiently dissociated than the $\mathrm{HD}^{16} \mathrm{O}$ ones $\left(R_{p}(\mathrm{D} / \mathrm{H}) \sim\right.$ $0.4)$, they will be just about 1.025 times more efficiently dissociated than the $\mathrm{H}_{2}^{18} \mathrm{O}$ ones $\left(R_{p}\left({ }^{18} \mathrm{O} /{ }^{16} \mathrm{O}\right) \sim 0.975\right)$.

\section{Code availability}

The spectral fitting and retrievals were performed using the NEMESIS radiative transfer and retrieval algorithm ${ }^{29}$. The code can be downloaded from https://doi.org/10.5281/zenodo.4303976.

\section{Data availability}

The datasets generated by the ExoMars Trace Gas Orbiter instruments analysed in this study are available in the ESA Planetary Science Archive (PSA) repository, https://archives.esac.esa.int/psa, following a six months prior access period, following the ESA Rules on Information, Data and Intellectual Property. The data products generated in this study (retrieved atmospheric parameters) are available on https://github.com/juanaldayparejo/opendata. 


\section{Figure Legends}

Figure 1. Example of ACS MIR spectra and summary of the retrieval scheme. ACS MIR spectra shown in this figure was obtained in orbit 4409 (A) (Latitude $=42^{\circ} \mathrm{S}, \mathrm{L}_{s}=291^{\circ}$, Local time $=19 \mathrm{~h}$ ). In step 1 of the retrieval scheme, pressure and temperature based on the absorption of $\mathrm{CO}_{2}(\mathrm{~B})$, and $\mathrm{H}_{2}^{16} \mathrm{O}$ volume mixing ratio profiles are retrieved from one detector row in diffraction orders 223 and 224 (A). In step 2, spectra from five different detector rows (C) are independently used to retrieve the volume mixing ratios of $\mathrm{H}_{2}^{16} \mathrm{O}, \mathrm{H}_{2}^{18} \mathrm{O}$ and $\mathrm{HD}^{16} \mathrm{O}$ (D) from the spectral window in diffraction order 224 , which allow the derivation of the $\mathrm{D} / \mathrm{H}$ and ${ }^{18} \mathrm{O} /{ }^{16} \mathrm{O}$ isotope ratios $(\mathrm{E})$.

Figure 2. Climatology of the retrieved atmospheric parameters. The panels show the values of the retrieved parameters as a function of altitude and solar longitude for the northern (left) and southern (right) hemispheres. A) Distribution of ACS MIR solar occultation observations, with the local time represented by the colour bar. B) Atmospheric temperature. C) Water vapour volume mixing ratio. D) D/H ratio in water vapour with uncertainties lower than $1 \mathrm{VSMOW}$.

Figure 3. Seasonal evolution of the isotopic fractionation of $\mathrm{D} / \mathrm{H}$ during the photodissociation of water vapour. A) Evolution of the observational coverage of ACS MIR secondary grating position 4 observations. B) The column-integrated photolysis rate of water vapour (red curve) exhibits large seasonal variations, revealing the perihelion season to be dominant in the production of $\mathrm{OH}$ and $\mathrm{H}$. The estimated fractionation factor $R$ between the value representative of the lower atmosphere $(\mathrm{D} / \mathrm{H}=4.9 \mathrm{VSMOW})$ and its photodissociation products (blue curve) also shows substantial seasonal variations, showing the largest fractionation during aphelion. C) The relative contribution of condensation-induced $\left(R_{c}\right)$ and photolysis-induced $\left(R_{p}\right)$ fractionation to the total fractionation $R$ demonstrate the prevalence of the latter in shaping the isotopic composition of the photolysis products.

\section{Figures}

\section{Extended Figures}



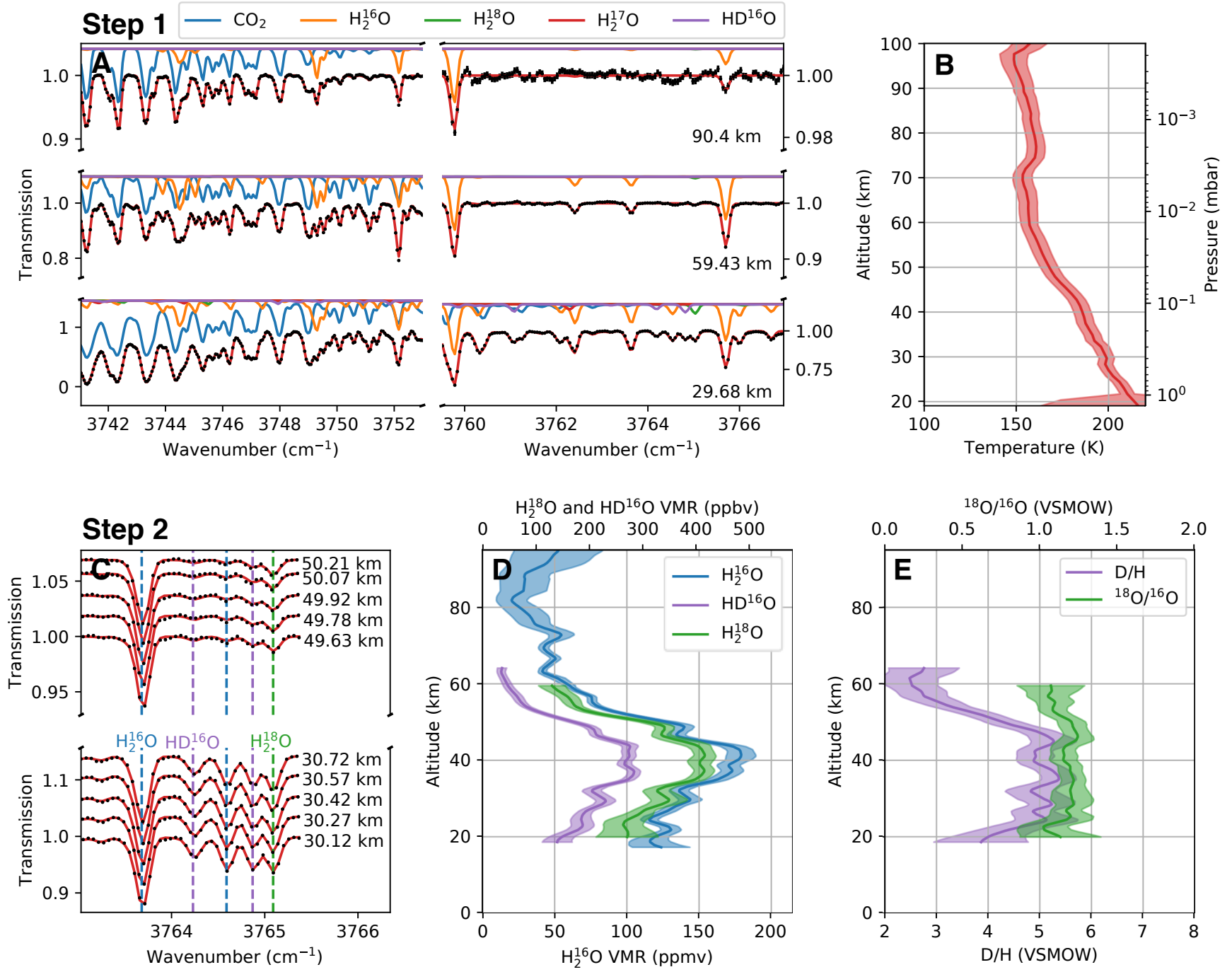

Figure 1. Example of ACS MIR spectra and summary of the retrieval scheme. ACS MIR spectra shown in this figure was obtained in orbit 4409 (A) (Latitude $=42^{\circ} \mathrm{S}, \mathrm{L}_{s}=291^{\circ}$, Local time $\left.=19 \mathrm{~h}\right)$. In step 1 of the retrieval scheme, pressure and temperature based on the absorption of $\mathrm{CO}_{2}(\mathrm{~B})$, and $\mathrm{H}_{2}^{16} \mathrm{O}$ volume mixing ratio profiles are retrieved from one detector row in diffraction orders 223 and 224 (A). In step 2, spectra from five different detector rows (C) are independently used to retrieve the volume mixing ratios of $\mathrm{H}_{2}^{16} \mathrm{O}, \mathrm{H}_{2}^{18} \mathrm{O}$ and $\mathrm{HD}^{16} \mathrm{O}$ (D) from the spectral window in diffraction order 224, which allow the derivation of the $\mathrm{D} / \mathrm{H}$ and ${ }^{18} \mathrm{O} /{ }^{16} \mathrm{O}$ isotope ratios (E). 

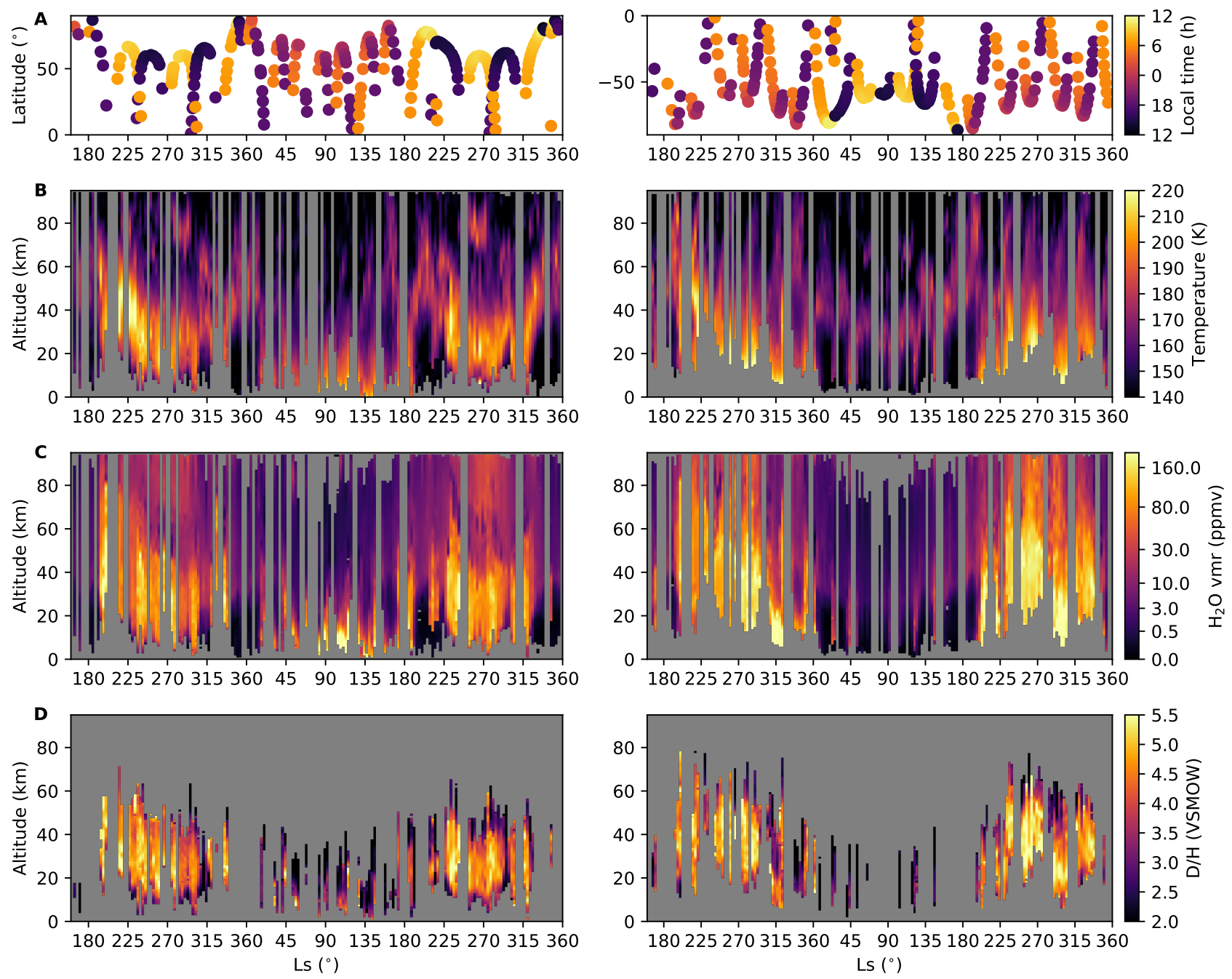

Figure 2. Climatology of the retrieved atmospheric parameters. The panels show the values of the retrieved parameters as a function of altitude and solar longitude for the northern (left) and southern (right) hemispheres. A) Distribution of ACS MIR solar occultation observations, with the local time represented by the colour bar. B) Atmospheric temperature. C) Water vapour volume mixing ratio. D) $\mathrm{D} / \mathrm{H}$ ratio in water vapour with uncertainties lower than 1 VSMOW. 

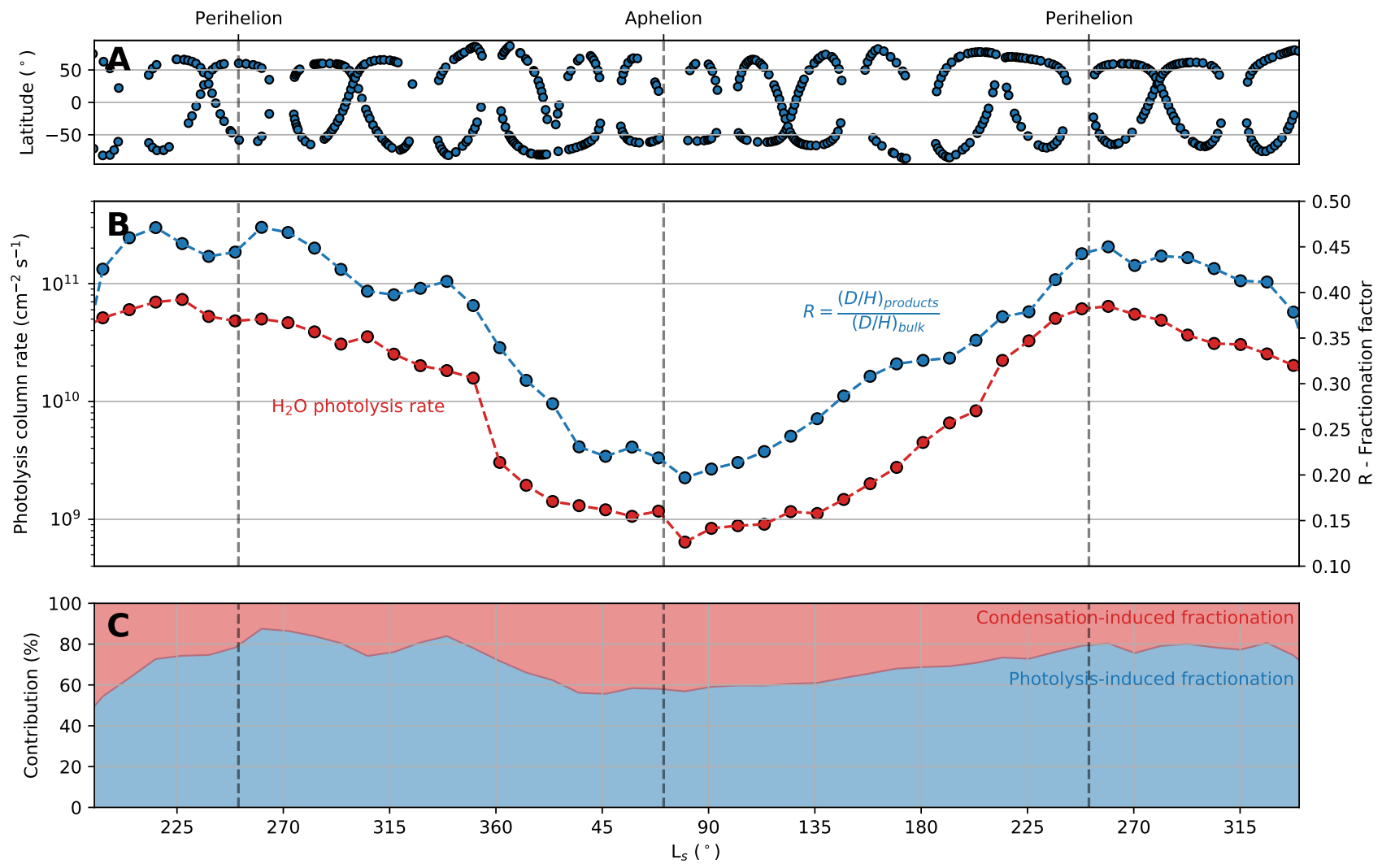

Figure 3. Seasonal evolution of the isotopic fractionation of $\mathrm{D} / \mathrm{H}$ during the photodissociation of water vapour. $\mathrm{A}$ ) Evolution of the observational coverage of ACS MIR secondary grating position 4 observations. B) The column-integrated photolysis rate of water vapour (red curve) exhibits large seasonal variations, revealing the perihelion season to be dominant in the production of $\mathrm{OH}$ and $\mathrm{H}$. The estimated fractionation factor $R$ between the value representative of the lower atmosphere $(\mathrm{D} / \mathrm{H}=4.9 \mathrm{VSMOW})$ and its photodissociation products (blue curve) also shows substantial seasonal variations, showing the largest fractionation during aphelion. C) The relative contribution of condensation-induced $\left(R_{c}\right)$ and photolysis-induced $\left(R_{p}\right)$ fractionation to the total fractionation $R$ demonstrate the prevalence of the latter in shaping the isotopic composition of the photolysis products. 

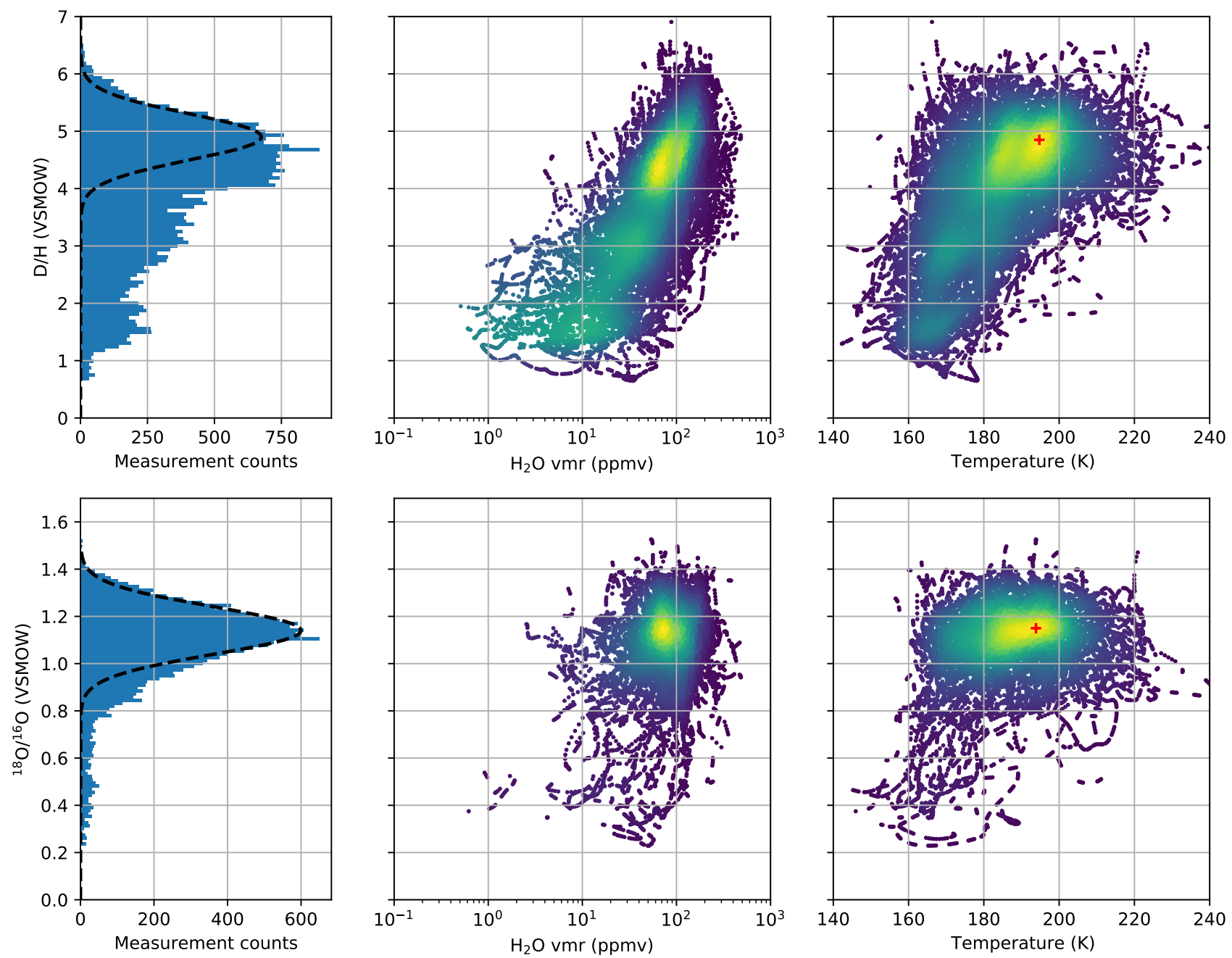

Extended Data Figure 1. Histogram of the measured $\mathrm{D} / \mathrm{H}$ and ${ }^{18} \mathrm{O} /{ }^{16} \mathrm{O}$ isotope ratios, as well as their relation with the water vapour mixing ratio and temperature. Only the points with uncertainties of $\mathrm{D} / \mathrm{H}<1 \mathrm{VSMOW}$ and ${ }^{18} \mathrm{O} /{ }^{16} \mathrm{O}<$ 0.13 VSMOW are shown. The black dashed lines on the histogram plots represent typical measurement uncertainties, centred at $\mathrm{D} / \mathrm{H}=4.9 \pm 0.4 \mathrm{VSMOW}$ and ${ }^{18} \mathrm{O} /{ }^{16} \mathrm{O}=1.14 \pm 0.11 \mathrm{VSMOW}$. The colour of the points on the plots in the middle and right columns represents the density of measured points. The red cross in the temperature panels represents the most frequently measured value of the isotope ratios at temperatures $>180 \mathrm{~K}$, which we take as the average non-fractionated isotope ratios in the Martian atmosphere. 

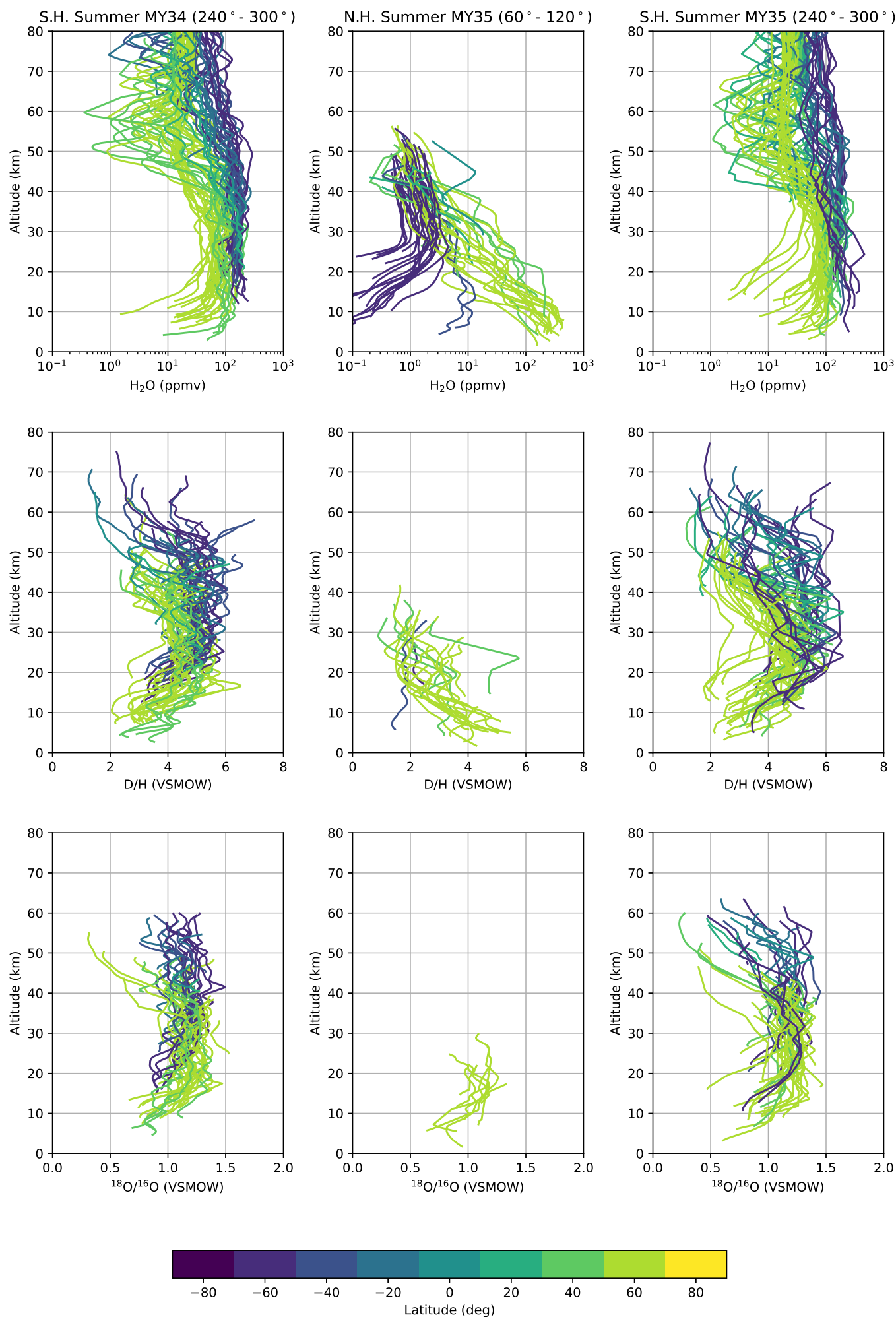

Extended Data Figure 2. Evolution of the water vapour mixing ratio and the $\mathrm{D} / \mathrm{H}$ and ${ }^{18} \mathrm{O} /{ }^{16} \mathrm{O}$ isotopic ratios in the perihelion and aphelion seasons of MY34 and MY35. The different panels show the retrieved profiles separated in different seasons, with the colour of the lines representing the latitude of the observations. For the clarity of the figure, only the points with uncertainties of $\mathrm{D} / \mathrm{H}<1$ VSMOW and ${ }^{18} \mathrm{O} /{ }^{16} \mathrm{O}<0.13$ VSMOW are shown. 

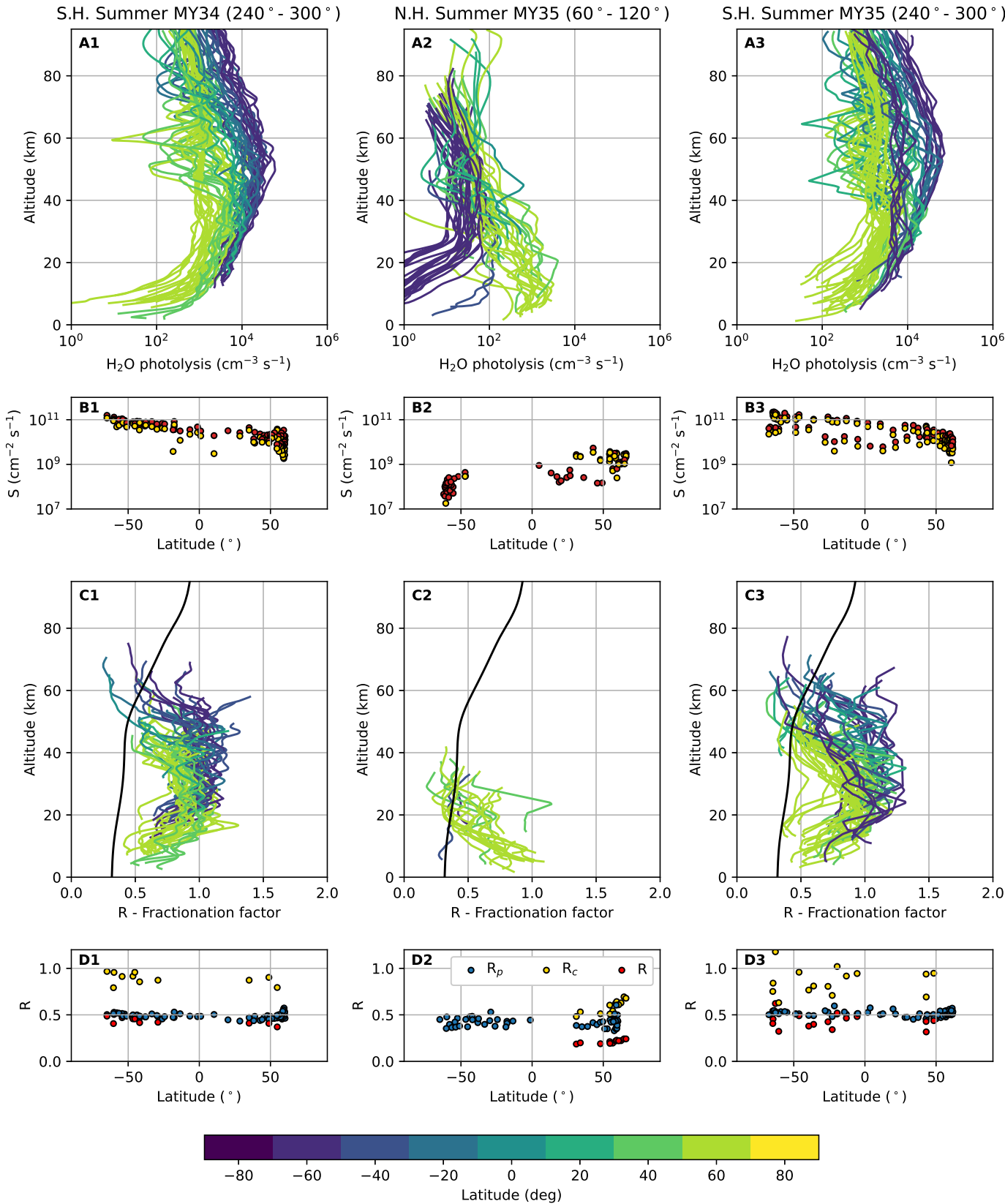

Extended Data Figure 3. Comparison of the estimated impact of fractionation during photolysis for the perihelion and aphelion seasons during MY34 and MY35. (A) Calculated $\mathrm{H}_{2} \mathrm{O}$ dissociation rates, with the colour of the lines representing the latitude of the observations. (B) Column-integrated photolysis rates (red dots) as a function of latitude. The yellow dots represent the column-integrated photolysis rates when using the part of the column in which the measurements are sensitive to HDO (C) Fractionation factor $R$ between the D/H ratio representative of water vapour in the lower atmosphere and that of the photolysis products for the cases of photolysis-induced (black line) and condensation-induced fractionation (coloured lines). (D) Column-integrated fractionation factor $R$ as a function of latitude for the cases of photolysis-induced (blue dots) and condensation-induced (yellow dots) fractionation, as well as the combination of the two (red dots). The condensation-induced fractionation factor is only plotted if the column-integrated photolysis rate using the part of the column in which the measurements are sensitive to HDO (yellow dots in B) is at least 75\% of that calculated when using the whole column (red dots in B). 

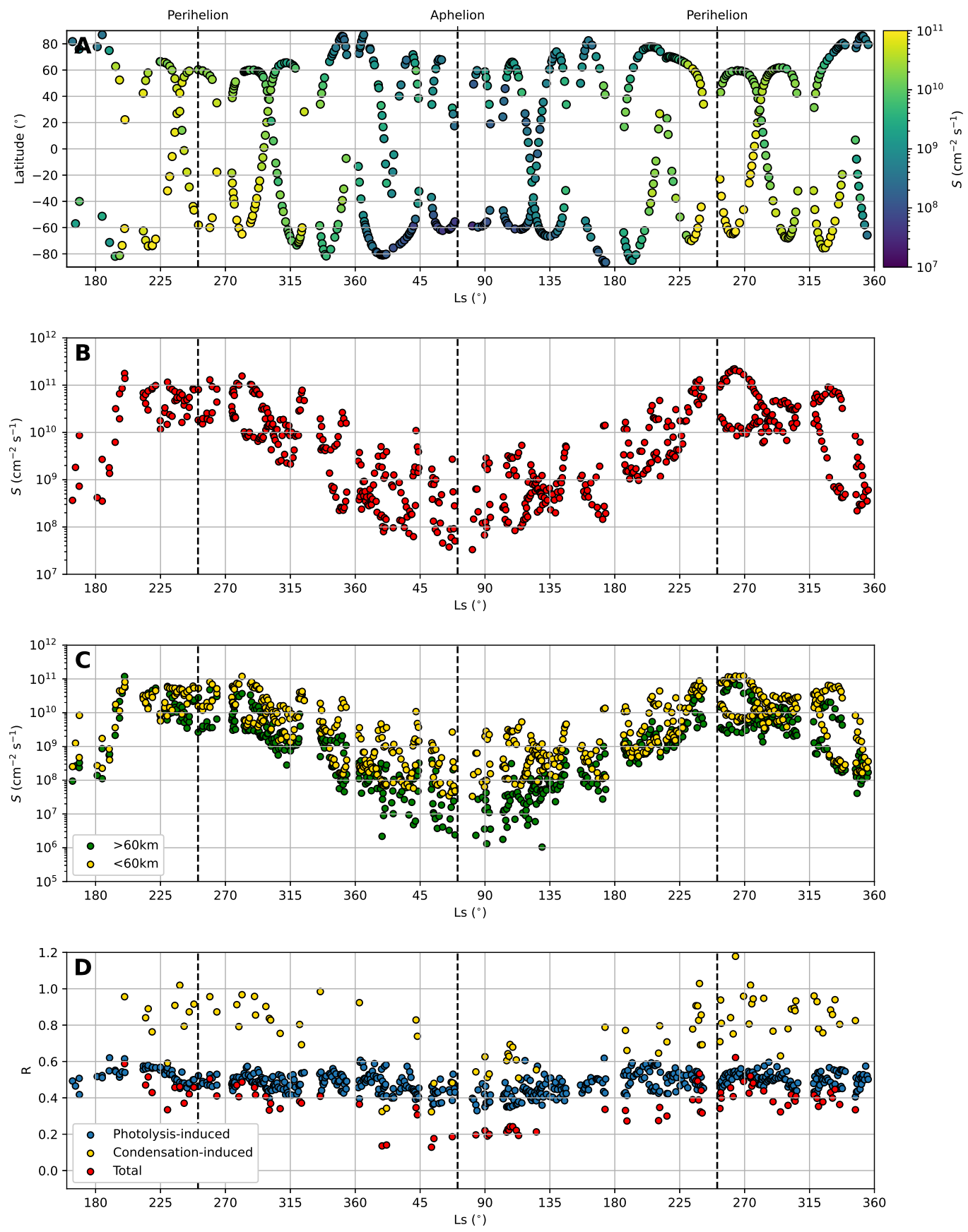

Extended Data Figure 4. Evolution of the water vapour photolysis rates and D/H fractionation factor. A) Latitudinal coverage of the ACS MIR observations, with the colour of the points representing the column-integrated photolysis rate of $\mathrm{H}_{2} \mathrm{O}$. B) Column-integrated photolysis rate of $\mathrm{H}_{2} \mathrm{O}$. C) Column-integrated photolysis rates of $\mathrm{H}_{2} \mathrm{O}$ above (green dots) and below (yellow dots) $60 \mathrm{~km}$. D) Column-integrated fractionation factor $R$ for the cases of photolysis-induced (blue dots) and condensation-induced (yellow dots) fractionation, as well as the combination of the two (red dots). 